\title{
Use of Text Messaging (SMS) for the Management of Side Effects in Cancer Patients Undergoing Chemotherapy Treatment: a Randomized Controlled Trial
}

\author{
Timóteo Matthies Rico ${ }^{1}$ (D) $\cdot$ Karina dos Santos Machado ${ }^{2} \cdot$ Vanessa Pellegrini Fernandes $^{3} \cdot$ Samanta Winck Madruga $^{3}$. \\ Mateus Madail Santin ${ }^{3}$. Cristiane Rios Petrarca ${ }^{3} \cdot$ Samuel Carvalho Dumith ${ }^{4}$
}

Received: 2 October 2019 / Accepted: 25 September 2020 / Published online: 30 September 2020

(C) Springer Science+Business Media, LLC, part of Springer Nature 2020

\begin{abstract}
Cancer patients are often not sufficiently oriented to manage side effects at home. Sending text messages with self-care guidelines aimed managing side effects is the main objective of this randomized controlled trial. Patients who started outpatient chemotherapy treatment between March and December 2017 at a hospital in southern Brazil were invited to participate in this study and were allocated to the intervention or control group (ratio 1: 1). Each patient in the intervention group received a daily SMS (short message service) with some guidance on management or prevention of side effects. All text messages were sent to the intervention group patients in an automated and tailored way by our app called cHEmotHErApp. Side effects experienced by patients were verified using the European Organization for Research and Treatment of Cancer Quality of Life Questionnaire Core-30 (EORTC QLQ-C30). Results showed intervention group patients experienced fewer side effects compared to the control group in cycle $1(p<0.05)$, in general. In addition, intervention group experienced less nausea in relation to the control group, in the cycle 1 and cycle $2(\mathrm{p}<0.05)$. This study indicate text messaging may be a tool for supporting side effect management in patients receiving chemotherapy. This study was enrolled in ClinicalTrials.gov with the identification number NCT03087422. This research was performed in accordance with the Declaration of Helsinki.
\end{abstract}

Keywords Telemedicine $\cdot$ Patient education $\cdot$ Self-management $\cdot$ Side-effects $\cdot$ Neoplasms $\cdot$ Text-messaging

\section{Introduction}

Chemotherapy is one of the main options in the treatment of cancer, and it is used to eradicate neoplastic cells through the

Electronic supplementary material The online version of this article (https://doi.org/10.1007/s10916-020-01663-x) contains supplementary material, which is available to authorized users.

Timóteo Matthies Rico timoteomr@gmail.com

1 Instituto Federal Sul-Rio-Grandense, Corredor das Tropas, 801, Jaguarão - Rio Grande do Sul, Jaguarão, RS 96300-000, Brazil

2 C3 - Centro de Ciências Computacionais, Universidade Federal do Rio Grande, Rio Grande do Sul, Rio Grande, Brazil

3 Hospital Escola, Universidade Federal de Pelotas, Rio Grande do Sul, Pelotas, Brazil

4 Programa de Pós Graduação em Ciências da Saúde, Universidade Federal do Rio Grande, Rio Grande do Sul, Rio Grande, Brazil administering of drugs, and can be applied in combination with radiotherapy or surgery $[1,2]$. Available antineoplastic drugs do not specifically act on tumor cells, which often leads to the elimination of healthy cells [2]. Consequently, it can cause toxicity to organs, inducing side effects such as fever, nausea, vomiting, fatigue, diarrhea, mucositis, pain, among others $[1,3]$.

These adverse effects can compromise quality of life, increase financial costs, diminish adherence to treatment and cause medical complications [3, 4]. In addition, the financial costs of managing side effects of chemotherapy and the demand for better health care are increasing, potentially compromising cancer treatment [5]. Thus, there is an incentive for the development of cost-effective methods to prevent or ameliorate undesirable side effects [5].

Most people receive cancer treatment on an outpatient basis and manage side effects of the disease and treatment while at home [6]. Thus, developing patients' self-care skills is critically important to ensure safe and high quality care at home [7]. The mobile phone is cited as the most widely adopted 
technology on the planet $[8,9]$. The ubiquity and capabilities of this type of mobile telecommunication technology has spawned a rapidly growing line of research and practice in the health care field, called mHealth (mobile health) [10].

mHealth can be broadly defined as the usage of information technology and communication applied to the health field through mobile technology, assisting patients, populations and health professionals in improving health care. mHealth has the potential to transform the face of health service delivery across the globe [11], leading to the adequacy of health care and patients' quality of life, and ultimately the improvement of health care services. Thus, mHealth can play an important role in health care procedures in the treatment of cancer, tackling the management of side effects, and empowering patients and care providers in regard to self-care [10]. In this COVID-19 era, mHealth interventions are an even more attractive strategy, to minimize patient's exposure $[12,13]$.

One of the most used features in mHealth is text messaging (short message service - SMS), since this technology is one of the most utilized functions in mobile phones, representing one of the most widely employed communication methods in the world, and an inexpensive intervention modality [14]. Review studies concluded that SMS text messaging can serve as a tool to support patient self-management $[15,16]$. Also, SMS text message interventions are capable of producing positive change in the form of preventive health behaviors [17].

The majority of patients desired to receive as much information as possible about chemotherapy-related side effects [1]. The degree of satisfaction that cancer patients express about the information they receive has been associated with positive health outcomes, specifically regarding quality of life, performance status, side effects, and psychological well-being [18]. However, cancer patients may not receive adequate support to manage side effects at home [19]. Some studies report that patients received little information from their health team about the management of treatment-related side effects $[3,20]$.

Several approaches based on text messaging (SMS) method for communication have been used in cancer treatment, both in preventive measures [21-26] and in clinical care situations [27-30]. Specifically in chemotherapy, there are different intervention methods that employ SMS to monitor side effects as nausea, vomiting, and other symptoms, as well as in relation to patient adherence to their treatment. Few published articles focus on the usage of SMS messaging to manage the side effects of chemotherapy in combating cancer. We can highlight the following studies, conducted in Singapore from November 2011 to January 2012, and in United States from November 2014 and September 2015, respectively $[27,29]$. Both studies proved the feasibility of the usage of this technology to monitor side effects provoked by chemotherapy considering not randomized controlled trials. In addition, these studies found that text messaging does not interfere in the daily activities of patients. However, these studies did not focus on the prevention of side effects.

In our previous study, we showed the acceptance and perception of cancer patients undergoing chemotherapy on an outpatient basis receiving daily text messages about prevention and managing side effects, as well as emotional support [30]. Some patients reported, through text messages, they felt more confident in treatment, felt supported and encouraged, therefore facilitating self-care. Other patients reported they received new information about self-care, and that the messages helped them to take better care of themselves. Thus, all patients participating in that study reported receiving text messages helped them better cope with treatment because they received useful self-care information about treatment through text messages. In addition, the adherent patients reported they would recommend these text messages to other patients initiating chemotherapy for cancer [30].

From our previous results [30], we improved the present study expanding it to a considerable number of cancer patients, in order to verify other outcomes. To our knowledge, the present study is the first clinical trial employing text messaging (SMS) with preventative advice and side effect management tips sent to cancer patients in outpatient chemotherapy. The primary objective of this study was to determine if the text messages received by the patients lead to a reduction in side effects brought on by chemotherapy. In addition, we verified clinical feasibility of sending SMS text messages with self-care content to oncological patients.

\section{Materials and methods}

\section{Study design and management}

This research was a two-arm, Randomized Controlled Trial (RCT), not blinded. The research is registered in Plataforma Brasil and received the approval of the Research Ethics Committee of the Faculty of Medicine of the Federal University of Pelotas with the Certificate of Presentation for Ethical Appreciation (CAAE) 47,707,315.9.0000.5317. Also, this study was enrolled in ClinicalTrials.gov with the identification number NCT03087422. This research was performed in accordance with the Declaration of Helsinki.

\section{Study setting}

Pelotas is a municipality located in the southern region of the state of Rio Grande do Sul, Brazil. With a population of approximately 343,000 inhabitants, it is considered the third most populous city in the state. The present study was performed at the Oncology Service (Chemotherapy) of the School Hospital (HE) of the Federal University of Pelotas 
(UFPel). This HE/UFPel has full capability to execute projects related to new actions and policies directed to SUS (Unified Health System), since it is a reference in the area of oncology and it is supported $100 \%$ by SUS, as well as characterized as a sentinel hospital. In addition, HE/UFPel serves patients from 22 municipalities.

\section{Participants}

Adult patients (18 to 70 years of age) diagnosed with cancer, who started the first outpatient chemotherapy treatment scheme between March and December of 2017 in HE/ UFPel, were invited to participate in the study.

Participants needed to have their own cell phone, be literate and be able to speak and read in Portuguese. All participants also needed to sign the Free and Informed Consent Form.

\section{Procedures}

Participants were randomized to one of two trial arms (intervention and control) in a 1:1 ratio, one by one, as they started chemotherapy treatment. The participants assigned to the intervention group received a SMS text message on their own cell phones on a daily basis, free of charge. In addition, patients in the intervention group were not required to respond to these text messages. All participants received standard care, which included instructions and information provided by oncologists, nurses, nutritionist, psychologist, pharmacists, among others.

These text messages have content about the prevention of side effects as well as emotional support. The messages were sent automatically on a daily basis to each patient in the intervention group utilizing the application cHEmotHErApp, developed by our group according to the methodology presented by Rico et al. [30].

The text messages containing advice were drafted in simple, clear, and objective language, in order to facilitate understanding with the patients. These messages were based on guidelines from the National Cancer Institute [31], as well as international cancer manuals [32] and were prepared by a multidisciplinary team, with the support of the medical and nursing team of the oncology service of the HE/UFPel. All of the messages were drafted and sent in Brazilian Portuguese. The messages are listed in the Supplementary file .

In order that each patient in the intervention group receive advice on dealing with the most common side effects, the messages were divided by themes. Thus, the configuration of each message in cHEmotHErApp, beyond registering the message itself, was also configured according to the theme covered. The messages were drafted and divided in nine themes: physical activity, hydration, emotional support, nausea/vomiting, constipation/diarrhea, hygiene, eating, immunity, and changes in the skin and sense of taste. For each of these themes, various pieces of advice were drafted and sent. In many cases the messages dealt with more than one side effect.

The algorithm of cHEmotHErApp for the automatic sending of text messages is timed with the treatment period of each patient [30], and does not send messages with the same theme for at least 5 consecutive days. In addition, the algorithm does not repeat messages for a period of at least 45 days. Thus, the process of receiving the text messages is dynamic because each day every patient received a tailored message with a different topic. The patients in the control group received only standard care, and answered the questionnaires periodically.

\section{Data collection and analysis}

The first interview with each study patient was performed at the time of their first chemotherapy session. In this interview, the patients answered the socio-demographic questionnaire (age, sex, schooling, and marital status), as well as signed the free and informed consent term of the research. In addition, the ECOG scale (Eastern Cooperative Oncology Group) was applied aiming to qualify the patients' well-being and capacity for self-care. The type of cancer of each patient was verified directly in the medical records of the HE/UFPel Oncology Service.

The European Organization for Research and Treatment of Cancer Quality of Life Questionnaire Core-30 (EORTC QLQC30) [33] was employed as the base to verify the presence of side effects. In this questionnaire, patients from both groups responded if they experienced a side effect. The presence of 14 side effects were verified: changes in the skin, changes in the sense of taste, fatigue, fever, diarrhea, pain, lack of appetite, shortness of breath, indigestion, mouth lesions, weakness, constipation, nausea, and vomiting.

On the first day of the cycle 2 , cycle 3 , and cycle 4 cycle, patients from both groups were interviewed using the questionnaire to measure the side effects experienced in the previous cycle. Or rather, in the beginning of the cycle 2 , the side effects experienced in the cycle 1 were verified, in the beginning of the cycle 3 the side effects experienced in the cycle 2 , and finally, in the beginning of the cycle 4 the side effects experienced in the cycle 3 . In addition, in the beginning of the cycle 4 the patients of the intervention group were asked if they read the received messages on a daily basis, and if the received text messages were considered helpful in their treatment. In addition, these patients were asked whether or not they had followed the guidelines received through text messages (followed all guidelines, followed almost all guidelines, followed half guidelines, followed a few guidelines). Besides, these patients were asked about the level of satisfaction of the text messages received (very satisfied, satisfied, neither satisfied nor dissatisfied, dissatisfied, very dissatisfied).

All interviews were conducted face-to-face with consenting patients while they were receiving the 
chemotherapy infusion. All the questionnaires were read to the patients, which has been shown to reveal more detailed and accurate information than written surveys, in order to reduce possible misclassification bias [34] related to the low levels of education of some patients in Brazil. All interviews were conducted by main researcher.

We used the exact Fisher test and the chi-square test to compare groups (intervention and control) regarding side effects. To compare the number of symptoms for each group along the cycles we used the Wilcoxon paired test. The significance level was set as 0.05 for two-tailed tests. Intentionto-treat analysis was applied to all cycles. Data analysis were performed in March 2018 using Stata software, version 11.2.

\section{Results}

In total, 118 patients participated in this study, 59 in each group (Fig. 1). The losses of participants (16 patients in the intervention group, and 15 patients in the control group) were due to death, abandonment of treatment, patient hospitalization, or treatment interruption. In addition, some patients ended their treatment in less than four cycles. Almost 4\% (6 patients) of the patients were not included in the study for being illiterate, and thus, they were excluded from randomization. No patient refused to participate in the study.

In the cycle 1,54 patients of the intervention group and 59 patients of the control group were included in intention-totreat analysis. In the cycle 2, 46 patients of the intervention group and 52 patients of the control group were included in intention-to-treat analysis. In the cycle 3, 43 patients of the intervention group and 44 patients of the control group were included in intention-to-treat analysis.

The most prevalent types of cancer in the participants were breast cancer, colon cancer and lung cancer. The majority of the participants were older than 50 and were married. Also, it was observed in patients of both groups that a large majority had never finished elementary school. Most patients were between the scale of $0-1$ on the ECOG, which implies good capacity for self-care and completion of daily tasks. Both groups were similar in the studied characteristics (Table 1).

Each patient in the intervention group received, on average, 52 SMS text messages from the first day of treatment to the beginning of the cycle 4. All text messages were sent automatically via cHEmotHErApp in the morning. All patients in the intervention group attested to have read daily the received text messages. Besides, these patients have considered text messages received were helpful to cope with treatment. Regarding the satisfaction in receiving the text messages, 31 patients $(72.1 \%)$ reported being very satisfied, and 12 patients $(27.9 \%)$ reported being satisfied. Regarding the followed guidelines from text messages received, 28 patients $(65.1 \%)$ reported to have followed all text messages, 14 patients $(32.6 \%)$ reported to have followed almost all text messages, and 1 (2.3\%) patient reported to have followed half of them.

It can be observed on Table 2 intervention group experienced less multiple side effects in the cycle 1, compared to the control group. However, this result was in the limit of statistical significance $(p=0.05)$. In the cycle 2 and cycle 3 , both groups were equivalent with regard to multiple experienced side effects. More than $93 \%$ of the patients in the control group experienced multiple side effects in the first three cycles of treatment, on average. However, in the intervention group, the rate of multiple side effects throughout the first three cycles was closer to $85 \%$ on average $(p=0.24)$. In the cycle 1 , cycle 2 and cycle 3 the patients from the intervention group had, on average, 4.4, 4.8, and 5.1 side effects, respectively. On the other hand, the patients from the control group in the cycle 1 , cycle 2 and cycle $3 \mathrm{had}$, on average, 5.5, 5.4, and 5.4 side effects, respectively.

The side effects most observed in the first three cycles of treatment in the control group were nausea $(73 \%)$, fatigue $(60 \%)$, and changes in the sense of taste $(57 \%)$. In the intervention group, the most common side effects were fatigue (53\%), weakness $(49 \%)$ and nausea (49\%) (Fig. 2).

Table 3 shows how many patients experienced (or not) each of the side effects analyzed, by group and cycle. Two (nausea and indigestion) of the 14 side effects measured showed statistical significance between both groups (Table 3). There was significantly higher reports of nausea in the control group in the cycle $1(p=0.034)$ and in the cycle $2(p=0.001)$, compared to the intervention group. Whilst not reaching statistical significance, there is a trend for intervention group experience less nausea in the cycle 3 compared to the control group $(p=0.06)$. Besides, there was significantly higher reports of indigestion in the control group in the cycle $1(p=0.04)$, compared to the intervention group.

The intervention group showed far less average of side effects in the cycle 1, compared with the control group ( $p=$ 0.01 ). In the cycle 2 , the intervention group also showed less average of side effects when compared with the control group, but in the limit of statistical significance $(p=0.05)$. In the cycle 3 , there was no significant difference in side effects between both groups $(p=0.76)$.

There was a change in the mean of the total sum of experienced side effects in intervention group. It was observed intervention group had an increase total sum of experienced side effects from cycle 1 to cycle 2 , from cycle 2 to cycle 3 , and from cycle 1 to cycle 3 . On the other hand, the total sum of the experienced side effects remained stable in the control group over the three cycles analyzed, from cycle 1 to cycle 2 , from cycle 2 to cycle 3 , and from cycle 1 to cycle 3 (Table 4). 
Fig. 1 Flowchart of enrollment, and follow-up of study participants from March 2017 to December 2017

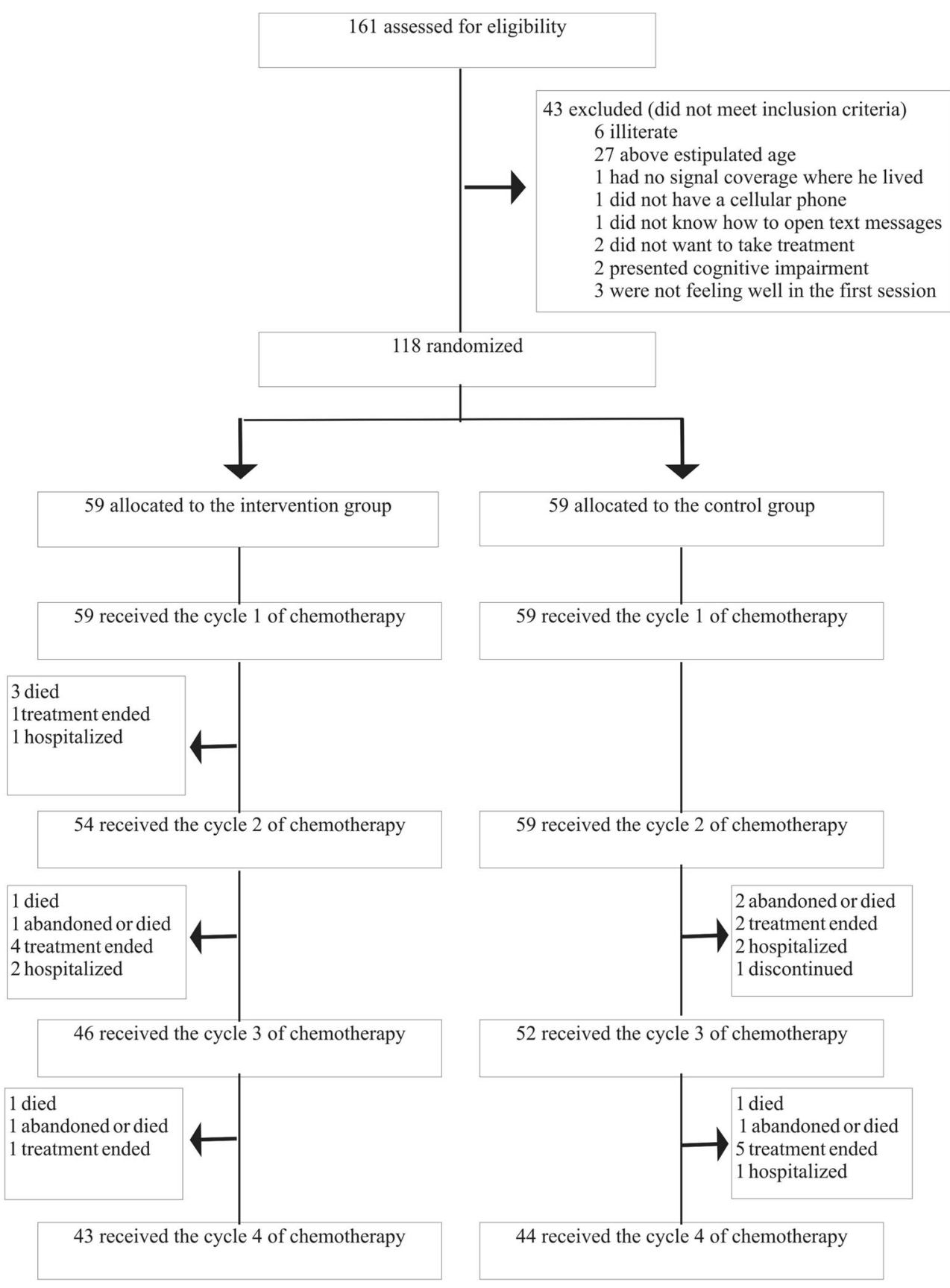

\section{Discussion}

This intervention sent one text message a day from the 1st day of chemotherapy to the beginning of the fourth cycle for each patient of the intervention group, with general and accessible guidelines on self-care for cancer patients. In addition, this intervention did not focus on the prevention and management of a specific side effect, but informed the patients regarding the relief of the most experienced side effects. However, more self-care behaviors text messages were used for nausea than for the other side effects experienced by subjects. Thus, the results of this clinical trial are directly related to the elaborate text messages, and to the algorithm of sending the SMS by cHEmotHErApp.

The prevention and management of chemotherapy-induced nausea and vomiting (CINV) is a priority in the oncology setting [35]. Incidence of vomiting has been substantially reduced, but efforts to control nausea have been less successful, with nausea continuing to effect upward of $60 \%$ of patients [36]. Nausea was the symptom most frequently encountered in the patients of the control group in our study. Seventy-three per cent of the patients in the control group, on average, reported some degree of nausea throughout the first three cycles, whereas $49 \%$ of the patients of the intervention group 
Table 1 Characteristics of the study participants enrolled from March 2017 and December 2017 ( $n=118,59$ in each group)

\begin{tabular}{|c|c|c|c|}
\hline Characteristics & $\begin{array}{l}\text { Intervention group } \\
\text { n }(\%)\end{array}$ & $\begin{array}{l}\text { Control group } \\
\text { n }(\%)\end{array}$ & $p$ value \\
\hline \multicolumn{4}{|l|}{ Age } \\
\hline $18-30$ & $2(3.4)$ & $3(5.1)$ & \multirow{5}{*}{0.912} \\
\hline $31-40$ & $5(8.5)$ & $7(11.9)$ & \\
\hline $41-50$ & $10(16.9)$ & $11(18.6)$ & \\
\hline $51-60$ & $22(37.3)$ & $22(37.3)$ & \\
\hline $61-70$ & $20(33.9)$ & $16(27.1)$ & \\
\hline \multicolumn{4}{|l|}{ Sex } \\
\hline Male & $30(50.9)$ & $22(37.3)$ & \multirow[t]{2}{*}{0.194} \\
\hline Female & $29(49.1)$ & $37(62.7)$ & \\
\hline \multicolumn{4}{|l|}{ Residence } \\
\hline Urban & $41(69.5)$ & $50(84.7)$ & \multirow[t]{2}{*}{0.078} \\
\hline Rural & $18(30.5)$ & $9(15.3)$ & \\
\hline \multicolumn{4}{|l|}{ Marital status } \\
\hline Married & $38(64.4)$ & $39(66.1)$ & \multirow{4}{*}{0.865} \\
\hline Divorced & $8(13.6)$ & $9(15.2)$ & \\
\hline Widowed & $8(13.6)$ & $5(8.5)$ & \\
\hline Single & $5(8.4)$ & $6(10.2)$ & \\
\hline \multicolumn{4}{|l|}{ Race } \\
\hline White & $47(79.6)$ & $42(71.2)$ & \multirow{4}{*}{0.444} \\
\hline Black & $6(10.2)$ & $10(16.9)$ & \\
\hline Indigenous & $1(1.7)$ & $0(0.0)$ & \\
\hline Brown & $5(8.5)$ & $7(11.9)$ & \\
\hline \multicolumn{4}{|l|}{ Schooling } \\
\hline Elementary incomplete & $43(72.9)$ & $35(59.3)$ & \multirow{5}{*}{0.246} \\
\hline Elementary complete & $8(13.5)$ & $12(20.3)$ & \\
\hline High School complete & $5(8.5)$ & $9(15.3)$ & \\
\hline Undergraduate & $3(5.1)$ & $1(1.7)$ & \\
\hline Graduate & $0(0.0)$ & $2(3.4)$ & \\
\hline \multicolumn{4}{|l|}{ Performance status - ECOG } \\
\hline 0 & $12(20.3)$ & $14(23.7)$ & \multirow{4}{*}{0.723} \\
\hline 1 & $39(66.1)$ & $33(55.9)$ & \\
\hline 2 & $4(6.8)$ & $6(10.2)$ & \\
\hline 3 or 4 & $4(6.8)$ & $6(10.2)$ & \\
\hline \multicolumn{4}{|l|}{ Cancer type } \\
\hline Breast & $15(25.4)$ & $23(38.9)$ & \multirow{7}{*}{0.429} \\
\hline Gastrointestinal & $19(32.2)$ & $11(18.6)$ & \\
\hline Lung & $9(15.2)$ & $8(13.6)$ & \\
\hline Reproductive system (male/female) & $7(11.9)$ & $4(6.8)$ & \\
\hline Blood & $5(8.5)$ & $4(6.8)$ & \\
\hline Urinary & $2(3.4)$ & $3(5.1)$ & \\
\hline Other & $2(3.4)$ & $6(10.2)$ & \\
\hline
\end{tabular}

experienced some degree of nausea in the first three cycles on average. This clinical trial significantly reduced the symptoms of nausea in the patients that were subject to intervention, in the first and second cycle. The messages sent to the patients of this study focused on preventing nausea, taking into account that this was the side effect most feared by the patients.
This intervention reduced side effects in cycle 1 compared to the control group, on average. However, the mean of the experienced side effects remained stable in the control group over the three cycles analyzed, but in the intervention group it increased. The increase of total sum of experienced side effects in intervention group from cycle 1 to cycle 3 could be 
Table 2 Multiple side effects experienced by study participants enrolled from March 2017 and December

\begin{tabular}{lcc}
\hline Side effects experienced & $\begin{array}{l}\text { Intervention group } \\
\text { n patients }(\%)\end{array}$ & $\begin{array}{l}\text { Control group } \\
\text { n patients }(\%)\end{array}$ \\
\hline Cycle 1 ( $n=54$ intervention group; $n=59$ control group) & $17(28.8)$ \\
None to 3 & $26(48.1)$ & $42(71.2)$ \\
4 to 14 & $28(51.9)$ & \\
Cycle $2(n=46$ intervention group; $n=52$ control group) & $14(26.9)$ \\
None to 3 & $17(37.0)$ & $38(73.1)$ \\
4 to 14 & $29(63.0)$ & $15(34.1)$ \\
Cycle $3(n=43$ intervention group; $n=44$ control group) & $29(65.9)$ \\
None to 3 & $19(44.2)$ & 0.05 \\
4 to 14 & $24(55.8)$ & 0.38 \\
\hline
\end{tabular}

because the intervention group showed an immediate improvement, reducing the side effects in cycle 1 in comparison to the control group. Although the total sum of experienced side effects in intervention group from cycle 1 to cycle 3 has increased, on average the side effects of intervention group was lower in cycle 2 and cycle 3 compared to the control group, however, this average was statistical significance only in cycle 1 . No strategy for managing the side effects used by control patients was effective, because there was no prevention of any side effects and no decrease in average of side effects in the three cycles analyzed.

The Intensity of side effects vary among patients receiving the same antineoplastic drugs [37]. Thus, the side effects may be more diverse and the reactions of patients more variable and individualistic [38]. Besides, many side effects increase and became more severe over time, including changes in taste, nausea, and vomiting [39, 40]. Spichiger et al. showed a significant increase in number of symptoms experienced from 9.8 at the start of chemotherapy to 14.4 by cycle 3 [41]. Another study also found a gradual increase in experienced side effects from the first until fifth cycle [38]. In addition, some side effects are difficult to prevent and to control through self-care behaviors, including taste changes, nausea, vomiting, weakness, and fatigue [39, 42]. Hence, management and prevention of side effects using self-care behaviors may not always be effective in all cycles of chemotherapy.

We have decided to use the SMS focusing one-way communication, which might restrict the potential of this technique. A review study identified two-way (sending text messages and receiving replies) text messaging is better than one-
Fig. 2 Side effects experienced by study participants enrolled from March 2017 and December 2017

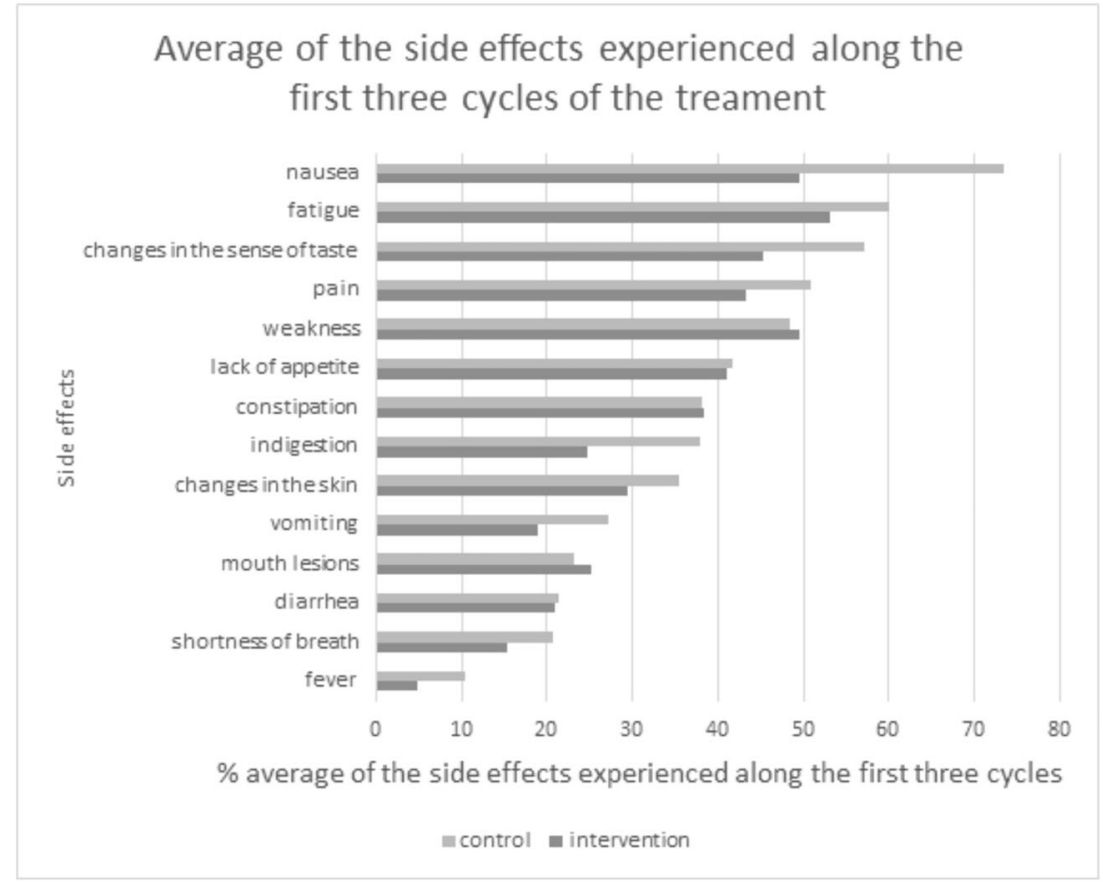


Table 3 Side effects experienced by study participants enrolled from March 2017 and December 2017

\begin{tabular}{|c|c|c|c|c|c|c|c|c|c|c|}
\hline \multirow[b]{2}{*}{ Symptom } & \multirow[b]{2}{*}{ Group } & \multicolumn{3}{|c|}{$\begin{array}{l}\text { cycle } 1(n=54 \text { intervention group; } \\
n=59 \text { control group) }\end{array}$} & \multicolumn{3}{|c|}{$\begin{array}{l}\text { cycle } 2(n=46 \text { intervention group; } \\
n=52 \text { control group) }\end{array}$} & \multicolumn{3}{|c|}{$\begin{array}{l}\text { cycle } 3(n=43 \text { intervention group; } \\
n=44 \text { control group) }\end{array}$} \\
\hline & & $\begin{array}{l}\text { Not } \\
\text { experienced } \\
\mathrm{n}(\%)\end{array}$ & $\begin{array}{l}\text { Experienced } \\
\mathrm{n}(\%)\end{array}$ & $\begin{array}{l}\mathrm{p} \\
\text { value }\end{array}$ & $\begin{array}{l}\text { Not } \\
\text { experienced } \\
\mathrm{n}(\%)\end{array}$ & $\begin{array}{l}\text { Experienced } \\
\mathrm{n}(\%)\end{array}$ & $\begin{array}{l}\mathrm{p} \\
\text { value }\end{array}$ & $\begin{array}{l}\text { Not } \\
\text { experienced } \\
\mathrm{n}(\%)\end{array}$ & $\begin{array}{l}\text { Experienced } \\
\mathrm{n}(\%)\end{array}$ & $\begin{array}{l}\mathrm{p} \\
\text { value }\end{array}$ \\
\hline Changes in skin & $\begin{array}{l}\text { Intervention } \\
\text { Control }\end{array}$ & $\begin{array}{l}43(79.6) \\
43(72.9)\end{array}$ & $\begin{array}{l}11(20.4) \\
16(27.1)\end{array}$ & 0.509 & $\begin{array}{l}30(65.2) \\
33(63.5)\end{array}$ & $\begin{array}{l}16(34.8) \\
19(36.5)\end{array}$ & 1000 & $\begin{array}{l}28(65.1) \\
24(54.5)\end{array}$ & $\begin{array}{l}15(34.9) \\
20(45.5)\end{array}$ & 0.384 \\
\hline $\begin{array}{l}\text { Changes in sense of } \\
\text { taste }\end{array}$ & $\begin{array}{l}\text { Intervention } \\
\text { Control }\end{array}$ & $\begin{array}{l}35(66.0) \\
27(48.2)\end{array}$ & $\begin{array}{l}18(34.0) \\
29(51.8)\end{array}$ & 0.060 & $\begin{array}{l}25(55.6) \\
20(40.0)\end{array}$ & $\begin{array}{l}20(44.4) \\
30(60.0)\end{array}$ & 0.153 & $\begin{array}{l}17(39.5) \\
17(39.5)\end{array}$ & $\begin{array}{l}26(60.5) \\
26(60.5)\end{array}$ & 1000 \\
\hline Fatigue & $\begin{array}{l}\text { Intervention } \\
\text { Control }\end{array}$ & $\begin{array}{l}28(51.9) \\
25(42.4)\end{array}$ & $\begin{array}{l}26(48.1) \\
34(57.6)\end{array}$ & 0.349 & $\begin{array}{l}21(45.7) \\
20(38.5)\end{array}$ & $\begin{array}{l}25(54.3) \\
32(61.5)\end{array}$ & 0.540 & $\begin{array}{l}18(41.9) \\
17(38.6)\end{array}$ & $\begin{array}{l}25(58.1) \\
27(61.4)\end{array}$ & 0.829 \\
\hline Diarrhea & $\begin{array}{l}\text { Intervention } \\
\text { Control }\end{array}$ & $\begin{array}{l}43(79.6) \\
46(78.0)\end{array}$ & $\begin{array}{l}11(20.4) \\
13(22.0)\end{array}$ & 1000 & $\begin{array}{l}37(80.4) \\
44(84.6)\end{array}$ & $\begin{array}{l}9(19.6) \\
8(15.4)\end{array}$ & 0.605 & $\begin{array}{l}33(76.7) \\
32(72.7)\end{array}$ & $\begin{array}{l}10(23.3) \\
12(27.3)\end{array}$ & 0.806 \\
\hline Pain & $\begin{array}{l}\text { Intervention } \\
\text { Control }\end{array}$ & $\begin{array}{l}33(61.1) \\
28(47.5)\end{array}$ & $\begin{array}{l}21(38.9) \\
31(52.5)\end{array}$ & 0.186 & $\begin{array}{l}25(54.3) \\
24(46.2)\end{array}$ & $\begin{array}{l}21(45.7) \\
28(53.8)\end{array}$ & 0.544 & $\begin{array}{l}23(53.5) \\
24(54.5)\end{array}$ & $\begin{array}{l}20(46.5) \\
20(45.5)\end{array}$ & 1000 \\
\hline Lack of appetite & $\begin{array}{l}\text { Intervention } \\
\text { Control }\end{array}$ & $\begin{array}{l}32(60.4) \\
31(55.4)\end{array}$ & $\begin{array}{l}21(39.6) \\
25(44.6)\end{array}$ & 0.699 & $\begin{array}{l}24(53.3) \\
27(54.0)\end{array}$ & $\begin{array}{l}21(46.7) \\
23(46.0)\end{array}$ & 1000 & $\begin{array}{l}27(62.8) \\
29(67.4)\end{array}$ & $\begin{array}{l}16(37.2) \\
14(32.6)\end{array}$ & 0.821 \\
\hline Shortness of breath & $\begin{array}{l}\text { Intervention } \\
\text { Control }\end{array}$ & $\begin{array}{l}45(83.3) \\
45(76.3)\end{array}$ & $\begin{array}{l}9(16.7) \\
14(23.7)\end{array}$ & 0.484 & $\begin{array}{l}38(82.6) \\
40(76.9)\end{array}$ & $\begin{array}{l}8(17.4) \\
12(23.1)\end{array}$ & 0.617 & $\begin{array}{l}38(88.4) \\
38(86.4)\end{array}$ & $\begin{array}{l}5(11.6) \\
6(13.6)\end{array}$ & 1000 \\
\hline Fever & $\begin{array}{l}\text { Intervention } \\
\text { Control }\end{array}$ & $\begin{array}{l}52(96.3) \\
52(88.1)\end{array}$ & $\begin{array}{l}2(3.7) \\
7(11.9)\end{array}$ & 0.166 & $\begin{array}{l}42(91.3) \\
48(92.3)\end{array}$ & $\begin{array}{l}4(8.7) \\
4(7.7)\end{array}$ & 1000 & $\begin{array}{l}42(97.7) \\
39(88.6)\end{array}$ & $\begin{array}{l}1(2.3) \\
5(11.4)\end{array}$ & 0.202 \\
\hline Mouth lesions & $\begin{array}{l}\text { Intervention } \\
\text { Control }\end{array}$ & $\begin{array}{l}38(70.4) \\
45(76.3)\end{array}$ & $\begin{array}{l}16(29.6) \\
14(23.7)\end{array}$ & 0.527 & $\begin{array}{l}34(73.9) \\
41(78.8)\end{array}$ & $\begin{array}{l}12(26.1) \\
11(21.2)\end{array}$ & 0.637 & $\begin{array}{l}35(81.4) \\
33(75.0)\end{array}$ & $\begin{array}{l}8(18.6) \\
11(25.0)\end{array}$ & 0.605 \\
\hline Weakness & $\begin{array}{l}\text { Intervention } \\
\text { Control }\end{array}$ & $\begin{array}{l}32(59.3) \\
30(50.8)\end{array}$ & $\begin{array}{l}22(40.7) \\
29(49.2)\end{array}$ & 0.450 & $\begin{array}{l}22(47.8) \\
29(55.8)\end{array}$ & $\begin{array}{l}24(52.2) \\
23(44.2)\end{array}$ & 0.544 & $\begin{array}{l}18(41.9) \\
21(47.7)\end{array}$ & $\begin{array}{l}25(58.1) \\
23(52.3)\end{array}$ & 0.668 \\
\hline Indigestion & $\begin{array}{l}\text { Intervention } \\
\text { Control }\end{array}$ & $\begin{array}{l}43(79.6) \\
37(62.7)\end{array}$ & $\begin{array}{l}11(20.4) \\
22(37.3)\end{array}$ & 0.048 & $\begin{array}{l}35(77.8) \\
33(64.7)\end{array}$ & $\begin{array}{l}10(22.2) \\
18(35.3)\end{array}$ & 0.183 & $\begin{array}{l}29(67.4) \\
25(58.1)\end{array}$ & $\begin{array}{l}14(32.6) \\
18(41.9)\end{array}$ & 0.504 \\
\hline Constipation & $\begin{array}{l}\text { Intervention } \\
\text { Control }\end{array}$ & $\begin{array}{l}28(51.9) \\
33(55.9)\end{array}$ & $\begin{array}{l}26(48.1) \\
26(44.1)\end{array}$ & 0.708 & $\begin{array}{l}31(67.4) \\
34(65.4)\end{array}$ & $\begin{array}{l}15(32.6) \\
18(34.6)\end{array}$ & 1000 & $\begin{array}{l}29(67.4) \\
29(65.9)\end{array}$ & $\begin{array}{l}14(32.6) \\
15(34.1)\end{array}$ & 1000 \\
\hline Nausea & $\begin{array}{l}\text { Intervention } \\
\text { Control }\end{array}$ & $\begin{array}{l}27(50.0) \\
18(30.5)\end{array}$ & $\begin{array}{l}27(50.0) \\
41(69.5)\end{array}$ & 0.034 & $\begin{array}{l}26(56.5) \\
12(23.1)\end{array}$ & $\begin{array}{l}20(43.5) \\
40(76.9)\end{array}$ & 0.001 & $\begin{array}{l}19(44.2) \\
11(25.0)\end{array}$ & $\begin{array}{l}24(55.8) \\
33(75.0)\end{array}$ & 0.060 \\
\hline Vomiting & $\begin{array}{l}\text { Intervention } \\
\text { Control }\end{array}$ & $\begin{array}{l}42(77.8) \\
42(71.2)\end{array}$ & $\begin{array}{l}12(22.2) \\
17(28.8)\end{array}$ & 0.519 & $\begin{array}{l}38(82.6) \\
37(71.2)\end{array}$ & $\begin{array}{l}8(17.4) \\
15(28.8)\end{array}$ & 0.235 & $\begin{array}{l}36(83.7) \\
34(77.3)\end{array}$ & $\begin{array}{l}7(16.3) \\
10(22.7)\end{array}$ & 0.590 \\
\hline
\end{tabular}

way text messaging (sending text messages only) to improve medication adherence [43]. Another study suggested

Table 4 Analysis of total sum of experienced side effects by study participants enrolled from March 2017 and December 2017 (Paired ttest or Wilcoxon paired test)

\begin{tabular}{llllll}
\hline Cycle & \multicolumn{2}{l}{ Intervention } & & & Control \\
\cline { 2 - 3 } \cline { 5 - 6 } & Mean (Std) & p value & & Mean (Std) & p value \\
\hline 1 & $20.088(0.758)$ & 0.030 & & $24.897(1.041)$ & 0.333 \\
2 & $21.466(0.846)$ & & & $23.897(0.939)$ & \\
2 & $21.348(0.881)$ & 0.017 & & $23.627(1.042)$ & 0.889 \\
3 & $23.279(1.212)$ & & & $23.744(0.937)$ & \\
1 & $20.116(0.791)$ & 0.001 & & $25.093(1.112)$ & 0.255 \\
3 & $23.279(1.212)$ & & $23.744(0.937)$ & \\
\hline
\end{tabular}

interventions that provided and combined information, monitoring, feedback, and self-management could be more promising than interventions that only provided information to the patients [40]. It is possible that the intervention patients did not feel as engaged with text messages in cycle 2 and cycle 3 as in cycle 1 , since $35 \%$ of the intervention patients did not followed all guidelines received through the text messages, but, they followed almost all these guidelines. Thus, the increase of total sum of experienced side effects in the intervention group, and the general improvement only in cycle 1, may be partly attributed to the one-way communication that may have affected patient engagement.

Side effects can frequently be prevented and/or managed with supportive medications when they are recognized early [44]. However, in this research we have decided to elaborate the text messages only with non-pharmacological orientations. It is possible that because we did not use 
pharmacological orientation in this intervention, made it difficult to reduce the side effects in all cycles, which it were only reduced in the first cycle. Still, study participants received pharmacological and non-pharmacological guidance from the treatment team.

Related works using mHealth applied to the management of side effects guided patients only after they indicated which symptom they were experiencing [27, 44]. In addition, these studies instructed patients with pharmacological and non-pharmacological orientations. Rather than wait for side effects to develop, intervention might be used to prepare patients for treatment and the expected challenges to quality of life [45]. Besides, the goal of symptoms management may not always be to prevent symptoms from occurring, but rather reduce impact on daily life [40]. In our study, we instructed patients regarding prevention and management of side effects in antecipatory mode, sending daily guidelines on self-care even if patients were not experiencing a particular symptom. Sending daily pieces of advice via text messaging helped patients to learn more about self-care, leading them to take better care of themselves. According to D'Haese et al., providing information in a stepwise fashion may be more beneficial than provide information all at once [46].

According to Schofield and Chambers [47], a new intervention must also be acceptable to both patients and clinicians. This present intervention found great acceptance with the participating patients, as well as all the health professionals involved (doctors, nurses, nutritionists, psychologists, social workers and other professionals). All of the participants in the intervention group were very grateful for all the text messages received, and they reported that the text messages helped to better confront their treatment. In addition, even though they were not requested to respond to the text messages, many patients expressed gratitude for the advice they received. All intervention patients who started cycle 4 were satisfied or very satisfied about the received text messages. Thus, this intervention showed clinical feasibility. The results of this study indicate the use of text messaging may be a tool for supporting side effect management in patients receiving chemotherapy.

Patients require preparation before beginning chemotherapy, which is commonly a very stressful time [48]. Incorporating text messages into prechemotherapy education may be useful. For example, changes in the taste could be more easily prevented if, since prechemotherapy, patients already received guidelines for prevention of this symptom based on behavior changes [49], since changes in the taste was the most increased experienced side effect from cycle 1 to cycle 3 in the intervention group.

The side effect evaluation questionnaire was not carried out in the residence of each patient when they experienced side effects. Side effects tend to be under-reported both qualitatively and quantitatively if they are reported after the fact [50]. Nevertheless, if this occurred, it occurred with both groups.

Possible additional factors could have influenced in the effect of the intervention. The type or quantity of additional information that the patients from both groups could have received from family members, friends, and the media (newspapers, television, and internet) could have interfered in this study. Likewise, even in outpatient treatment, the information that patients could have received from the treatment team could have interfered in the intervention. We did not control or evaluate this kind of information. However, the demographic characteristics and patient illness of both groups were similar and, thus, the results should not contain significant estimation errors.

Text messaging technology in cell phones can lead to the so-called Hawthorne effect [51], which provokes a change in behavior, in the case of the receipt of the messages, for the simple fact of the patient feeling cared for and appreciated. It is also believed that this effect is established by the patient's perception of their health care, which most certainly helps their self-care. Another limitation is possible contamination between both groups.

Some side effects experienced by the patients showed themselves to be almost statistically significant in comparing both groups. Nevertheless, other associations could not be found due to lack of statistical power.

Despite text message-based communication presenting numerous advantages, it is not also without its limitations. A potential limitation to the use of SMS text-message-based interventions is the possible marginalization of certain populations, such as those that are illiterate. Reduced visual acuity could be a potential limiting factor, making reading text messages difficult. In addition, unfamiliarity with SMS text messaging technology is another limitation, particularly among senior citizens. In this study, patients with cognitive impairments and above 70 years old were excluded.

\section{Conclusion}

This mHealth intervention proved to be an acceptable and feasible means to educate and support cancer patients undergoing chemotherapy treatment. The results of this study demonstrate that text messaging based intervention has the potential to manage side effects. Results of this clinical trial suggests that this intervention is associated with better chemotherapy-induced nausea related. Further studies with larger sample sizes are required to confirm these results and to further explore other benefits from text messaging in oncology setting.

This randomized controlled trial covered a broad spectrum of cancer patient characteristics. Thus, this 
intervention can be easily adapted and applied in other hospitals and clinics that carry out chemotherapy in treating cancer, benefiting the general oncological population. In conclusion, the results of this clinical trial could be used to guide the development and testing of new interventions. In addition, the present intervention can be expanded and applied in other health areas, whether it be via text messages with advice on the management of certain diseases, or even text messages about prevention of health-risk factors. Future studies may adapt this intervention to prevent a specific side effect, or even a symptom cluster. In addition, a possible adaptation of this intervention would be related to the algorithm of sending the text messages. Increasing frequency of sending text message could show other results. Besides, future studies could adapt this intervention exploring two-way communication.

Acknowledgments The authors thank all the patients who participated in the study and all the professionals of the Oncology Service of the School Hospital of the Federal University of Pelotas.

Authors' contributions Timóteo Matthies Rico: This author idealized and executed all the steps of this work: This author developed the cHEmotHErApp, did the interviews with the patients and wrote the manuscript.

Karina dos Santos Machado: This author assisted in the development of the research and revision of the manuscript.

Vanessa Pellegrini Fernandes: This author assisted in the elaboration of SMS and in technical issues during the research development, and revision of the manuscript.

Samanta Winck Madruga: This author assisted in the elaboration of SMS and in technical issues during the research development, and revision of the manuscript.

Mateus Madail Santin: This author assisted in technical issues during the research development, and revision of the manuscript.

Cristiane Rios Petrarca: This author assisted in the elaboration of SMS and in technical issues during the research development, and revision of the manuscript.

Samuel Carvalho Dumith: This author assisted in the development of the research, revision of the manuscript and contributed for statistical analysis.

\section{Compliance with ethical standards}

Ethics approval and consent to participate The research is registered in Plataforma Brasil and received the approval of the Research Ethics Committee of the Faculty of Medicine of the Federal University of Pelotas with the Certificate of Presentation for Ethical Appreciation (CAAE) 47,707,315.9.0000.5317. All participants signed the Free and Informed Consent Form.

Also, this study was enrolled in ClinicalTrials.gov with the identification number NCT03087422. This research was performed in accordance with the Declaration of Helsinki. This manuscript does not contain individual information. Participants were referred to generically as "patients," "participants," etc.

Conflict of interest Authors have no conflict of interest to declare.

\section{References}

1. Chan H-K, Ismail S. (2014) Side effects of chemotherapy among cancer patients in a Malaysian General Hospital: experiences, perceptions and informational needs from clinical pharmacists. Asian Pac J Can Prev 15: 5305-9.

2. Tacar O, Sriamornsak P, Dass CR. (2013) Doxorubicin: an update on anticancer molecular action, toxicity and novel drug delivery systems. J Pharm Pharmacol 65: 157-70.

3. Henry DH, Viswanathan HN, Elkin EP, Traina S, Wade S, Cella D. (2008) Symptoms and treatment burden associated with cancer treatment: results from a cross-sectional national survey in the US. Sup Care Can 16: 791-801.

4. Chen HC, Allan H, Lu ZY. (2013) The social construction of cancer chemotherapy toxicity: the case of Taiwan. Can Nursing 36: E61-7.

5. Carlotto A, Hogsett VL, Maiorini EM, Razulis JG, Sonis ST. (2013) The economic burden of toxicities associated with cancer treatment: review of the literature and analysis of nausea and vomiting, diarrhoea, oral mucositis and fatigue. Pharmacoeconomics 31: 753-66.

6. Stacey D, Bakker D, Ballantyne B, Chapman K, Cumminger J, Green E, et al. (2012) Managing symptoms during cancer treatments: evaluating the implementation of evidence-informed remote support protocols. Imp Sci 7: 110.

7. Breen S, Ritchie D, Schofield P, Hsueh Y-S, Gough K, Santamaria N, et al. (2015) The Patient Remote Intervention And Symptom Management System (PRISMS)-a telehealth-mediated intervention enabling real-time monitoring of chemotherapy side-effects in patients with haematological malignancies: study protocol for a randomised controlled trial. Trials 16: 472.

8. ICT. The World in 2015: ICT Facts and Figures. (2015) [cited 2017 2017-07-27]; Available from: http://www.itu.int/en/ITU-D/ Statistics/Documents/facts/ICTFactsFigures2015.pdf. Accessed 02 October 2019.

9. ICT. The World in 2009: ICT Facts and Figures. (2009) [cited 2017 2017-07-27]; Available from: https:/www.itu.int/net/TELECOM/ World/2009/newsroom/pdf/stats ict200910.pdf. Accessed 02 October 2019.

10. Nasi G, Cucciniello M, Guerrazzi C. (2015) The performance of mHealth in cancer supportive care: a research agenda. J Med Internet Res.17(1):e9.

11. Kay M, Santos J, Takane M. (2011) mHealth: New horizons for health through mobile technologies. WHO 64: 66-71; Available from: https://www.who.int/goe/publications/goe_mhealth_web. pdf. Accessed 02 October 2019.

12. Kotsen C, Dilip D, Carter-Harris L, O'Brien M, Whitlock CW, Leon-Sanchez S, Ostroff JS (2020) Rapid Scaling Up of Telehealth Treatment for Tobacco-Dependent Cancer Patients During the COVID-19 Outbreak in New York City Telemed J E Health 9:1-10.

13. Qualliotine JR, Orosco RK (2020) Self-removing passive drain to facilitate postoperative care via telehealth during the COVID-19 pandemic. Head Neck 42:1305-1307.

14. Cole-Lewis H, Kershaw T. (2010) Text messaging as a tool for behavior change in disease prevention and management. Epidmiol Rev 32: 56-69.

15. Hall AK, Cole-Lewis H, Bernhardt JM. (2015) Mobile text messaging for health: a systematic review of reviews. An Rev Pub Health 36: 93-415.

16. De Jongh T, Gurol-Urganci I, Vodopivec-Jamsek V, Car J, Atun R. (2012) Mobile phone messaging telemedicine for facilitating self management of long-term illnesses. Cochrane Database of Syst Rev, 12: CD007459. 
17. Armanasco AA, Miller YD, Fjeldsoe BS, Marshall AL. (2017) Preventive health behavior change text message interventions: a meta-analysis. Am J Prev Med 52: 391-402.

18. Feldman-Stewart D, Capirci C, Brennenstuhl S, Tong C, Abacioglu U, Gawkowska-Suwinska M, et al. (2010) Information needs of early-stage prostate cancer patients: a comparison of nine countries. Rad Oncol 94: 328-33.

19. Langius-Eklöf A, Crafoord M-T, Christiansen M, Fjell M, Sundberg K. (2017) Effects of an interactive mHealth innovation for early detection of patient-reported symptom distress with focus on participatory care: protocol for a study based on prospective, randomised, controlled trials in patients with prostate and breast cancer. BMC Can 17: 466.

20. Molassiotis A, Stricker C, Eaby B, Velders L, Coventry P. (2008) Understanding the concept of chemotherapy-related nausea: the patient experience. Eur J Can Care 17: 444-53.

21. Janda M, Youl P, Marshall AL, Soyer H, Baade P. (2013) The HealthyTexts study: A randomized controlled trial to improve skin cancer prevention behaviors among young people. Contem Clin Trials 35: 159-67.

22. Baker DW, Brown T, Buchanan DR, Weil J, Balsley K, Ranalli L, et al. (2014) Comparative effectiveness of a multifaceted intervention to improve adherence to annual colorectal cancer screening in community health centers: a randomized clinical trial. JAMA Int Med 174: 1235-41.

23. Chung IY, Kang E, Yom CK, Kim D, Sun Y, Hwang Y, et al. (2015) Effect of short message service as a reminder on breast self-examination in breast cancer patients: a randomized controlled trial. J Telemed Telecare 21: 144-50.

24. Youl PH, Soyer HP, Baade PD, Marshall AL, Finch L, Janda M. (2015) Can skin cancer prevention and early detection be improved via mobile phone text messaging? A randomised, attention control trial. Prev Med 71: 50-6.

25. Kerrison R, Shukla H, Cunningham D, Oyebode O, Friedman E. (2015) Text-message reminders increase uptake of routine breast screening appointments: a randomised controlled trial in a hard-toreach population. Brit J Can 112: 1005-10.

26. Hirst Y, Skrobanski H, Kerrison RS, Kobayashi LC, Counsell N, Djedovic N, et al. (2017) Text-message Reminders in Colorectal Cancer Screening (TRICCS): a randomised controlled trial. Brit J Can 116: 1408-14.

27. Yap KY, Low HX, Koh KS, Un M, Shih V, Chan A. (2013) Feasibility and acceptance of a pharmacist-run tele-oncology service for chemotherapy-induced nausea and vomiting in ambulatory cancer patients. Telem J e-health: Official J Am Telemed Ass 19: 387-95.

28. Coursaris, C. K., Spoelstra, S. L., Given, C. W., Sikorskii, A., Majumder, A., DeKoekkoek, T., Schueller, M., and Given, B. A. (2015) A health belief messaging framework and a randomized controlled trial of an SMS-based intervention for cancer patient outcomes. In: System Sciences (HICSS), 2015 48th Hawaii International Conference on System Scince. IEEE, pp 2866-2875.

29. Mougalian SS, Epstein LN, Jhaveri AP, Han G, Abu-Khalaf M, Hofstatter EW, et al. (2017) Bidirectional Text Messaging to Monitor Endocrine Therapy Adherence and Patient-Reported Outcomes in Breast Cancer. JCO Clin Can Inform 1: 1-10.

30. Rico TM, dos Santos Machado K, Fernandes VP, Madruga SW, Noguez PT, Barcelos CRG, et al. (2017) Text Messaging (SMS) Helping Cancer Care in Patients Undergoing Chemotherapy Treatment: a Pilot Study. J Med Syst 41: 181.

31. INCA. Instituto Nacional do Câncer. 2018 [cited 2018 2018-0326]; Available from: http://www.inca.gov.br/. Accessed 02 October 2019.

32. ASCO. American Society of Clinical Oncology. 2017 [cited 2017 2017-07-26]; Available from: https://www.asco.org/. Accessed 02 October 2019.
33. Franceschini J, Jardim JR, Fernandes ALG, Jamnik S, Santoro IL. (2010) Reproducibility of the Brazilian Portuguese version of the European Organization for Research and Treatment of Cancer Core Quality of Life Questionnaire used in conjunction with its lung cancer-specific module. J Bras Pneum 36: 595-602.

34. Patrick DL, Cheadle A, Thompson DC, Diehr P, Koepsell T, Kinne S. (1994) The validity of self-reported smoking: a review and metaanalysis. Am J Pub Health 84: 1086-93.

35. Marx W, McCarthy AL, Ried K, McKavanagh D, Vitetta L, Sali A, et al. (2017) The effect of a standardized ginger extract on chemotherapy-induced nausea-related quality of life in patients undergoing moderately or highly emetogenic chemotherapy: A double blind, randomized, placebo controlled trial. Nutrients 9: 867.

36. Souza CM, Visacri MB, Ferrari GB, Tuan BT, Costa APL, Barbosa CR, et al. (2015) Nausea, vomiting and quality of life of patients with cancer undergoing antineoplastic treatment: an evaluation by pharmacists. Int J Pharm Practice 23: 357-60.

37. Olver I. (2005) Update on anti-emetics for chemotherapy-induced emesis. Int Med J 35: 478-81.

38. Macquart-Moulin G, Viens P, Bouscary M, Genre D, Resbeut M, Gravis G, et al. (1997) Discordance between physicians' estimations and breast cancer patients' self-assessment of side-effects of chemotherapy: an issue for quality of care. Brit J Can 76: 1640.

39. Williams SA, Schreier AM. (2004) The effect of education in managing side effects in women receiving chemotherapy for treatment of breast cancer. Oncol Nursing Forum 31: E16-23.

40. Fridriksdottir N, Gunnarsdottir S, Zoëga S, Ingadottir B, Hafsteinsdottir E. (2018) Effects of web-based interventions on cancer patients' symptoms: review of randomized trials. Sup Care Can 26: 337-351.

41. Spichiger E, Müller-Fröhlich C, Denhaerynck K, Stoll H, Hantikainen V, Dodd M. (2011) Prevalence of symptoms, with a focus on fatigue, and changes of symptoms over three months in outpatients receiving cancer chemotherapy. Swiss Med Wkly 141: w13303.

42. Schloss J, Colosimo M, Vitetta L. (2016) New insights into potential prevention and management options for chemotherapy-induced peripheral neuropathy. Asia-Pac J Oncol Nursing 3: 73.

43. Wald DS, Butt S, Bestwick JP. (2015) One-way versus two-way text messaging on improving medication adherence: meta-analysis of randomized trials. The Am J Med 128: 1139. e1-. e5.

44. Kearney N, McCann L, Norrie J, Taylor L, Gray P, McGee-Lennon M, et al. (2009) Evaluation of a mobile phone-based, advanced symptom management system (ASyMSC) in the management of chemotherapy-related toxicity. Sup Care Can 17: 437-44.

45. Jacobsen PB, Meade CD, Stein KD, Chirikos TN, Small BJ, Ruckdeschel JC. (2002) Efficacy and costs of two forms of stress management training for cancer patients undergoing chemotherapy. J Clin Oncol 20: 2851-62.

46. D'haese S, VinhHung V, Bijdekerke P, Spinnoy M, de Beukeleer M, Lochie N, et al. (2000) The effect of timing of the provision of information on anxiety and satisfaction of cancer patients receiving radiotherapy. J Can Ed 15: 223-7.

47. Schofield P, Chambers S. (2015) Effective, clinically feasible and sustainable: Key design features of psycho-educational and supportive care interventions to promote individualised selfmanagement in cancer care. Acta Oncol 54: 805-12.

48. Aranda S, Jefford M, Yates P, Gough K, Seymour J, Francis P, et al. (2012) Impact of a novel nurse-led prechemotherapy education intervention (ChemoEd) on patient distress, symptom burden, and treatment-related information and support needs: results from a randomised, controlled trial. An Oncol: The Official J Europ Soc Med Oncol 23: 222-31.

49. Rehwaldt M, Wickham R, Purl S, Tariman J, Blendowski C, Shott S, et al., editors. (2009) Self-care strategies to cope with taste changes after chemotherapy. Oncol Nursing Forum, 36 (2) E47-56. 
50. Coolbrandt A, Van den Heede K, Vanhove E, De Bom A, Milisen $\mathrm{K}$, Wildiers H. (2011) Immediate versus delayed self-reporting of symptoms and side effects during chemotherapy: does timing matter? Europ J Oncol Nursing 15: 130-6.

51. McCarney R, Warner J, Iliffe S, Van Haselen R, Griffin M, Fisher P. (2007) The Hawthorne Effect: a randomised, controlled trial. BMC Med Res Method 7: 30.
Publisher's Note Springer Nature remains neutral with regard to jurisdictional claims in published maps and institutional affiliations. 